Full paper download:

http://dx.doi.org/10.1061/(ASCE)0733-9445(1983)109:9(2207)

or request a free copy from a-munoz-mancera@ northwestern.edu

\title{
CRACK SPACING IN REINFORCED CONCRETE: Approximate SOLUTION
}

By Zdeněk P. Bažant, ${ }^{1}$ F. ASCE and Byung $\mathrm{H}$. $\mathrm{Oh}^{2}$

In a companion paper in this issue (1), a simplified theory for predicting the spacing of cracks in a parallel crack system in reinforced concrete was presented. Due to the approximate nature of this theory, it would be reassuring to show that a different approximate analysis yields about the same result. For this purpose, we will now show a solution based on the formulas for the stress caused by a concentrated force in a half space. [All notations are the same as in the companion paper (1) and are summarized in Appendix III of this paper. The reader should also refer to this paper for an explanation of the type of fracture mechanics energy approach used.]

We now consider only sparse full length cracks, such that $s>b / 2$, because they are more likely to happen and are also simpler to analyze. We suppose that the total accumulated bond force, $P_{b}$, is transmitted from the steel bar into concrete at one point at a distance $\beta s / 2$ from the crack, in which $\beta=$ an empirical coefficient between 0.0 and 2.0 , probably $\beta \simeq 1.0$, and we imagine that the volume of concrete which is stressed by this force is a hemisphere whose radius, $R$, is such that its volume $2 \pi R^{3} / 3$ is equal to the actual volume of concrete limited by a normal plane through the point of application of $P_{b}$, i.e., to $b_{1} b_{2}(2 s-\beta s) / 2$ [Figs. $1(a)-(b)]$. This yields

$R=\left[\frac{3}{4 \pi} A s(2-\beta)\right]^{1 / 3} ; \quad A=b_{1} b_{2}$

For the stress in the hemisphere we use the Boussinesq-Kelvin solution for $v=1 / 2$ (Ref. 15 of preceding paper). This is the simplest form solution for the spread of a concentrated force. Although actual $v$ is about 0.2 , we use $v=0.5$ because the results are not very different and larger errors are caused by our other simplifications. For this solution, the stress state everywhere is a uniaxial stress in the radial direction, i.e.:

$\sigma_{r r}=C_{b} \frac{\cos \theta}{r^{2}} ; \quad C_{b}=\frac{3 P_{b}}{2 \pi}=\frac{3 F_{b} s}{2 \pi}$

All other stress components are zero. Here, $r, \theta=$ the spherical coordinates [Figs. 1(a)-(b)]; and $F_{b}=$ average distributed bond force.

We need to assure compatibility of the deformation due to $\sigma_{r r}$ with the average strain, $\epsilon_{b}$, of concrete at the bar surface due to $\sigma_{r r}$. This con-

${ }^{1}$ Prof. of Civ. Engrg. and Dir., Center for Concrete and Geomaterials, Technological Inst., Northwestern Univ., Evanston, Ill. 60201.

${ }^{2}$ Grad. Research Asst., Northwestern Univ., Evanston, III. 60201.

Note.-Discussion open until February 1, 1984. To extend the closing date one month, a written request must be filed with the ASCE Manager of Technical and Professional Publications. The manuscript for this paper was submitted for review and possible publication on April 22, 1982. This paper is part of the Journal of Structural Engineering, Vol. 109, No. 9, September, 1983. CASCE, ISSN 07339445/83/0009-2207/\$01.00. Paper No. 18211. 